\title{
In situ infiltration as influenced by cover crop and tillage management
}

\begin{abstract}
ABSTRCT
Water is usually the most limiting factor in agricultural grain crop production. Various agricultural management practices such as tillage and use of cover crops have the potential to influence water infiltration into soil. This study was conducted on a Waldron silt loam (fine, smectictic, calcareous, mesic Aeric Fluvaquents) soil to evaluate the influence of cover crop and tillage management on in situ infiltration. The field site included three replicate blocks in a randomized complete block design with each plot measuring $21.3 \mathrm{~m}(69.9 \mathrm{ft})$ length and

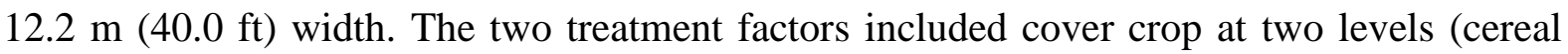
rye [Secale cereale] cover crop [CC] versus no cover crop [NC]) and tillage at two levels (moldboard plow tillage [Till] versus no-tillage [NT]). Continuous corn (Zea mays L.) was grown. Infiltration rates were measured in all the treatments using a Mariotte system with single ring infiltrometers during the 2014 and 2015 growing seasons. Water infiltration parameters were estimated using the Parlange and Green-Ampt infiltration equations. Parlange and Green-Ampt models appeared to fit measured data well with coefficient of variation ranging from 0.92 to 0.99 . In 2014, the saturated hydraulic conductivity (KS) parameter value determined from the Parlange model was $30.4 \mathrm{~mm} \mathrm{~h}-1$ for NT, about $42 \%$ greater than Till. The KS parameter value determined from the Green-Ampt model was 25.9 mm h-1 for NT, about 54\% greater than Till. In 2015, the sorptivity (S) parameter value determined from the Parlange model was $38.6 \mathrm{~mm}$ h- 0.5 for CC, about $82 \%$ greater than NC. The $\mathrm{S}$ parameter value determined from the Green-Ampt model was $34.0 \mathrm{~mm} \mathrm{~h}-0.5$ for CC, about $90 \%$ greater than NC. Cover crop management can increase water infiltration, which can improve soil quality and enhance the sustainability of crop production systems.
\end{abstract}

Keyword: Freeman farm; Green-ampt equation; Parlange equation; Ponded infiltration; Quasi; Steady infiltration rate; Sorptivity. 